Review

\title{
Preventive Production of Beer against Oxidation-Recent Advances in Brewing Technology
}

\author{
Masachika TAKASHIO and Ken SHINOTSUKA \\ Brewing Research Laboratories, Sapporo Breweries Ltd. Yaizu, Shizuoka 425-0013, Japan
}

Received January 13, 1998; Accepted March 25, 1998

\begin{abstract}
Attempts to find a solution to the problem of beer staling have been unremitting: hundreds of articles have been published during the last few years alone. This paper introduces recent developments in brewing science and discusses basic research into the formation of stale flavors, together with measures proposed and adopted to counter them. Included are advances made both in brewing technology and beer distribution systems, which help minimize staling, with an example of product temperature management used by a Japanese company.
\end{abstract}

Keywords: beer, oxidation, stale flavor, malt, hops

\section{Introduction-Staling Phenomenon of Beer}

Shelf life has become one of the most critical issues in beer quality, especially now that beer is produced and marketed both nationally and internationally. Among the problems, microbiological infection and haze formation (or colloidal instability) have been virtually solved through improvements to the production system and microbial hygiene. However, it remains for us to find a solution to the nagging problem that beer gradually loses its original fresh flavor, and that this flavor deterioration is inevitable. Now that volatile compounds (in the sub ppb level) can be determined by gas chromatograph-mass spectrometer (GC-MS), it is clear that a large number of compounds, often present at a very low level, contribute towards the overall flavor of beer. Those compounds causing undesirable stale flavors, e.g., cardboard, papery, or straw-like flavors, have been intensively researched and the mechanism of their production has been proposed. The real problem is how practically to exploit these findings and produce stale-free beer.

\section{Chemical Reactions: the "Central Dogma" of Beer} Staling

\section{1) The phenomena of beer staling}

The stale flavor of over-age beer has been shown to result from the formation of unsaturated volatile carbonyls, especially aldehydes, which have low thresholds. Carbonyl compounds, such as trans-2-nonenal, 2-methyl-butanal, phenylacetaldehyde, benzaldehyde, 2-furfural, $\gamma$-nonalactone and others, are believed to be staling components, but it is still unclear which of these compounds contribute to the stale flavor (Kamimura \& Kaneda, 1993; Huige,1993). The above compounds have been reported to be formed by the following pathways:

1. Strecker degradation of amino acids (Meilgaard, 1972; Blockmans et al., 1979; Kossa et al., 1979; Masschelein, 1980),

2. melanoidin-mediated oxidation of higher alcohols
(Hashimoto \& Kuroiwa, 1975),

3. oxidative degradation of isohumulones (Hashimoto \& Kuroiwa, 1975),

4. auto-oxidation of unsaturated fatty acids (Meilgaard, 1972),

5. enzymatic degradation of lipids (Stenroors et al., 1976; Kossa et al., 1979; Esterbauer \& Schauenstein, 1977),

6. aldol condensation of short-chain aldehydes (Moll \& Moll, 1990), and

7. secondary oxidation of long-chain aldehydes (Piendl et al., 1981; Van de Meerssche et al., 1983; Narziß et al., 1985).

Among the most important findings has been the discovery of the role of free radicals in beer oxidation. Scavengers of the hydroxyl radical (mannitol, ascorbic acid) reduced beer staling, while agents which elevate hydroxyl levels (e.g., peroxide/metals) increased beer staling (Bamforth \& Parsons, 1985).

Based on the findings from experiments with electron spin resonance spectroscopy, a deterioration pathway for beer has been proposed as follows: the generation of hydroxyl radicals from hydrogen peroxide by metal catalysis in beer, following the Fenton and Haber-Weiss reactions. These radicals could either oxidize isohumulones into aldehydes and ketones, or the hydroxyl radicals could initiate a series of radical reactions (Kaneda et al., 1989).

Current studies are further elucidating the mechanisms of the staling reaction. However, the problem remains on how to practically control these reactions. Staling precursors in beer are still being oxidized finally to aldehydes with resultant undesirable aromas: this is the "Central Dogma" of beer staling, as we can call it.

\section{2) Possible measures against staling reactions}

(1) Historical background

Because oxidation has been viewed as the main reaction participating in the staling of beer, the avoidance of oxygen pick-up has been the key fundamental strategy exploited to 
improve flavor stability, and such efforts have been made especially during the beer filling process (reducing the package oxygen level); some success has been achieved. However, a kinetic study of beer oxidation has revealed that antioxidants are associated with certain chain reactions of beer oxidation, that is, the antioxidants in beer consumed oxygen rapidly (André \& Moll,1986). Thus, improved flavor stability of beer can be expected to be practically achieved by exploiting the antioxidants occurring in raw materials. However, the reality is more complex than expected. For example, some precursors of stale flavor aldehydes were added to beer, which was stored for some period. The redox status of beers with a low oxygen content largely remained stable, but carbonyls formation proceeded even under reducing conditions (Thum et al, 1995). The new challenge for brewing scientists will be how to reduce the precursors of stale flavor in both the raw materials and finished beer.

\section{(2) Analytical methods}

From a practical point of view, quantitative descriptions have been devised based on scientific analytical procedures.

\section{Degree of staling}

The application of 2-thiobarbituric acid (TBA) was first used to measure the degree of meat rancidity, and this reagent came to be widely employed for evaluating the oxidation of food products. TBA was later revealed to be very sensitive to furfurals. Grigsby and Palamand (1976) found that there is a correlation between beer staling and TBA reactive substances in beer and proposed an analytical method for beer staling by measuring the absorbance of the pigment developed by the TBA reaction. A numerical interpretation of the sense for staleness is also very important in understanding the relationship between the human sense for staleness (by degree) and the data obtained by instrumental analysis.

To compensate for the lack of precision of organoleptic evaluation, statistical analysis of the tasting data is commonly applied. A profile method composed of several items was developed to describe, in detail, the staling appearance of beer (Furusho et al., 1998).

A physicochemical analysis is also available. Chemiluminescence data obtained with staled beer was shown to be coincident with an organoleptic test (Kaneda et al., 1990).

2. Reducing potential

Fresh beer is in a state of reduction, and any oxygen molecule present is promptly absorbed by the components of beer, as already mentioned. Thus, the measurement of dissolved oxygen does not always indicate the level of beer oxidation. On the other hand, the redox potential $(\mathrm{rH})$ of beer, which is determined by the nature of the raw materials, wort composition, the characteristics and physiological condition of the yeast, is reported to give a good indication of the stability of the beer (Galic et al., 1994).

Besides the measurement of the redox potential of beer, an analytical method for the reducing activity has been developed which employs the reagent, 1,1-diphenyl-2-picryl hydrazyl (DPPH) (Kaneda et al, 1995). A number of beer constituents, (+)-catechin, (-)-epicatechin, procyanidin B3, prodelphinidin $\mathrm{d}$ and others, were found to reduce the DPPH radical, including various polyphenols which are oxidized during the reactions that lead to staling. The polyphenols involved in this reaction are mainly derived from malt (Granshaw, 1967).

\section{(3) Exogenous antioxidants as alternative measures}

In some countries, exogenous compounds have been studied as antioxidants or radical scavengers. Vitamin $\mathrm{C}$ is common and still employed. Sulfite preparations have never been used in Japan, but have a long history in the beverage industry, until they were regarded as a health hazard. Although restricted to research laboratory experiments, one strain of brewers yeast has been genetically modified to produce more sulfites (as described later).

Some synthetic antioxidants (for example, potassium metasulfite and sodium isoascorbate, or a combination of both) were reported to cause flavor stability improvement in beer (Klimovitz \& Kindraka, 1989). Among naturally occurring antioxidants, the use of 2"-O-glucosylisovitexin, a flavonoid of the plants, was recently claimed for a patent (Hagiwara, 1997).

(4) Essential measures to counter "time elapsing" in a beer bottle

The previous ideas, which attempt to capitalize on exogenous antioxidants, are only a poor alternative and far from the ideal solution. Most brewing scientists have chosen the direction of exploiting contemporary research findings to realize optimum control of beer production which minimizes changes in beer flavor during storage in the package. The Central Dogma of beer staling indicates three possible approaches:

1. reduction of precursors of staling flavor,

2. suppression of the rate of oxidation, and

3. masking stale flavor.

None of these measures will be simple to realize; therefore research activities are continuing, involving both laboratories and breweries.

To look for practical solutions, it is first necessary to establish analytical methods to measure the phenomena and to then evaluate quantitatively the relationship between the effects and measuring techniques. The chosen measures were evaluated by an assortment of analytical methods at Sapporo Breweries Ltd. The analytical system comprised the following three areas:

1. the organoleptic analysis of staling aroma and taste (a profile method, Furusho et al., 1998),

2. instrumental analysis and feedback system of the reducing potential ascribed to compounds like melanoidins and polyphenols (Araki et al.,1998), and

3. chromatographic analyses by GC-MS and high performance liquid chromatography (HPLC) employed together to help interpret the physicochemical data (Shimizu et al., 1998).

This total, combined data was analyzed and shown to be effective in describing the phenomenon. It was then applied to evaluate the design of pipe lines, to optimize beer production, at all ten breweries, as part of the Anti-oxidative Production System (Takashio et al., 1998).

\section{Raw Materials}

Malted barley, hops, water and yeast are four common raw materials of beer. Often, unmalted cereals, such as wheat, rice, 
corn (maize) and other crops, are used as adjuncts. It is important to note that those raw materials are all influential in the flavor stability of the resultant beer. The influence of malt and hops will now be discussed.

As for stale related components, malt includes all of (1) precursors, (2) enzymes, and (3) antioxidants relating to beer staling. The very malting process, as well as the barley variety, decides the constituents of malt, as above. Hops are also important for the precursors of stale flavor, together with antioxidants, mainly anthocyanogens, such as leukocyanidin and leukodelphinidin (Harris,1956), which produce anthocyanins by reaction with acids. Harris and Rickettes (1959) described their determinative method. Anthocyanogens commonly appeared in the brewing literatures (Moll, 1987).

\section{1) Stale-related components}

(1) The precursors of stale flavor

Malt-derived lipids are believed to be among the precursors of such undesirable flavors. Above all, trihydroxy acid is the main precursor of trans-2-nonenal (an aldehyde) believed to be the principal source of the cardboard flavor. Fatty substances and linoleic acid in barley are oxidized to keto acid, which then dissociates to form nonenal. There is an opportunity to reduce these precursors during the brewhouse process, that is, by an elaborate separation of the wort from the turbid materials (lautering process, described later). This can result in a lower content of trihydroxy acid in the wort and beer and, hence, lead to an improvement in flavor stability (Drost, 1981; Drost et al., 1990).

However, lipids are a critical, positive factor for yeast metabolism. That is, cell membrane phospholipids determine the ethanol tolerance of yeast cell, and ester formation by yeast is stimulated by saturated fatty acids and inhibited by unsaturated ones. It must also be noted that the creamy, dense and white foam of beer has great charm for beer lovers, and excess lipid causes an impairment of foam (Letters, 1992).

Thus, no simple solution is possible where balance plays an important role.

(2) The enzymes participating in beer staling

Although non-enzymatic oxidation might not have a little influence, many articles have appeared solely in the area of enzymatic reactions. Whereas the precursors of carbonyl compounds are derived from the oxidation of unsaturated fatty acids during wort production, there are two classes of oxidative enzymes in barley and malt: lipoxygenase and peroxidase.

Malt lipoxygenase has two isoenzymes, designated LOX1 and LOX2. Irrespective of barley variety, these two different lipoxygenases always appear to co-exist; one of the two enzymes is much more thermostable than the other. This stable lipoxygenase survives partially after malt kilning and in the mash up to $70^{\circ} \mathrm{C}$. The possibility of the thermostable lipoxygenase having a microbial origin has been suggested (Martel et al., 1991). The characteristics of these isoenzymes of lipoxygenase were further studied, in detail. LOX 1 mainly produces 9-LOOH (a precursor of trans-2-nonenal), while LOX 2 catalyses 13-hydroxperoxide formation. If the activities of these enzymes could be successfully reduced or inhibited, the resulting beer would be resistant to the staling phenome- non (Hugues et al., 1994).

The suggested routes involve the oxidation of lipids to produce 9-hydroperoxide of linoleic acid (9-LOOH), an indirect precursor of trans-2-nonenal, either by a two-stage enzymatic reaction, in which lipase catalyses the breakdown of lipids into free fatty acids (these are then oxidized to 9-LOOH in a reaction catalyzed by lipoxygenase), or by auto-oxidation. It is coincidental that beers made from malt with high total lipoxygenase activity were poor in flavor stability (De Buck et al., 1997).

\section{(3) The antioxidants in malt and hops}

Malt and hops have been shown to contribute to the supply of antioxidant activity of the finished beer. The antioxidant activity of malt mainly results from polyphenols (anthocyanogens and polymerized polyphenols, so called tannins) and melanoidins (products of Maillard reaction, which give beer its specific color). The molecular oxygen was demonstrated to be absorbed onto the polyphenols (Owades \& Jakovac, 1966). The low molecular weight fraction of polyphenols, precipitable from wort and beer by polyvinylpyrolidone (PVPP), is called tannoids (Chapon, 1993a) and is additionally very important for beer haze stability (Chapon, 1993b). Adjuncts, like corn starch or purified raw materials, are almost free from such antioxidant activity. Hence, all malt beer shows stronger resistance against staling reaction than beer made using adjuncts.

Hops which are boiled with the wort and provide beer with bitterness and aroma are also an important source of antioxidants such as anthocyanogens. Freshly picked hops are said to have stronger antioxidant properties than dried hops. Hop cone is now used only occasionally, and processed hops are now used principally. This is largely because hop products (processed) are convenient for storage, transportation, dosing and standardization. Hop pellets and hop extracts are two typical hop products. The dried hops are milled and the powdered hops are then compressed into pellets (typically cylindrical pellet form). For the hop extract prepared by liquid $\mathrm{CO}_{2}$, supercritical $\mathrm{CO}_{2}$ or ethanol is preferably used nowadays; however, hop extracts do not contain anthocyanogens (Van Waesberghe,1996).

Research indicates that the aroma hop varieties have a generally higher level of polyphenolic substances compared with the bitter hop varieties. The extraction of polyphenols of malt and hops was studied by the same authors. The hop polyphenols are easily extracted in the wort, but barley polyphenols are poorly solubilized (Sorgl et al., 1997).

The properties of the antioxidants of malt and hops have been intensively studied during the brewing process. If the wort is hopped with cones or pellets, some portion of the hop anthocyanogens will be precipitated during boiling. Anthocyanogens are also known to promote haze formation in beers during extended periods of storage in a package. Beer brewed from low-proanthocyanidin malts exhibited improved chill haze stability, but it is interesting that flavor stability was not significantly changed for the beer (Baxter et al., 1987).

The antioxidant potential of malt depends not only on the variety of the barley but also on the malting process. With melanoidins, other important reductones are formed by the 
"Maillard reaction" which occurs during the process of malt kilning. (Maillard reaction proceeds also during the processes of wort boiling and fermentation.) A further complication is that the antioxidant efficacy depends on the nature of the compounds (Boivin et al., 1995). McMurrough et al. (1995) reported that $(+)$-catechin and procyanidin B3 (B: procyanidins with $10 \mathrm{OH}$ groups), might be beneficial to flavor stability; on the contrary, prodelphinidin B3 promotes oxidation.

Walters et al. (1997a) evaluated the activity of beer antioxidants by five different methods (chemiluminescent peak height suppression, chemiluminescent time delay, the deoxyribose assay for hydroxyl radicals, the cytochrome $\mathrm{C}$ assay for superoxide, and a lipid peroxidation assay). Among the compounds, they found that $(+)$-catechin and ferulic acid are most effective. These compounds were added to beer and the effects evaluated by GC and HPLC. (+)-Catechin was found to suppress the formation of some carbonyl compounds, but ferulic acid increased the formation of a carbonyl compound (Walters et al., 1997a).

The effects of the antioxidants $(+)$-catechin and ferulic acid on the rate of formation of carbonyl compounds were revealed to be more complex. It is postulated that the reaction depends upon both oxygen and temperature. Two mechanisms of carbonyl formation are thought possible: the first occurs at low levels of oxygen $(<0.1 \mathrm{ppm})$ and involves the formation of trans-2-nonenal. The second occurs on exposure to air, producing additional long-chain carbonyl compounds. The inhibitory activities of $(+)$-catechin and ferulic acid which affected carbonyl formation were caused by the second mechanism, and not the first (Walters et al., 1997b).

(4) Evaluation methods for malt regarding staling-resistant potential

The choice of appropriate raw materials is being recognized as important in making beer with a longer shelf life.

An analytical method has been devised to predict the staling potential of beer brewed from malt. This is the "wort nonenal potential" (an indicator of how soon fresh beer is likely to become stale). Combined with the lipoxygenase activity test, the wort nonenal potential has proved to be a useful indicator of the staling susceptibility of beer (Van Waesberghe \& Van Waesberghe, 1994).

Another method is the Swift test, by which samples are classified as oxidant, oxidant- neutral or antioxidant according to their effects (if any) on the rapidity of the oxidation of maize oil under controlled conditions. The oxidant or antioxidant character of malt depends on the conditions used during the malting process, especially during kilning (Van Waesberghe, 1996).

Among several types of malt, pale lager malt might be particularly problematic, because this type of malt is kilned lightly to fulfill color specifications, and lipoxygenase is not inactivated. Darker malts are more or less free from lipoxygenase activity and usually richer in antioxidant constituents (e.g., melanoidins, this will be discussed in the next section), but nevertheless do not necessarily exhibit an antioxidant Swift test response. Some pale lager malts do give an antioxidant reaction to the Swift test.

\section{2) Malting process}

Malting is the process in which barley turns into malt, and this process consists of steeping, germination, and finally kilning (Boivin \& Martel, 1991). There are several types of malts, Pilsner malt (pale malt), Dark malt (Munich type), Vienna malt, Crystal malt (Caramel malt), Brumalt (Brümalz), Roasted malt (Black malt), and others, which differ from one another in taste, color, aroma, foam and other qualities of the beer brewed.

As previously described, malt contains the precursors of stale flavor, the enzymes involved in the oxidation of precursors like fatty acids, and antioxidants such as polyphenols and Maillard reaction products. Regarding the staling resistant quality of beer, the choice of a variety of barley and malting conditions has been studied to minimize the activities of lipoxygenases and lipid oxidation products and to optimize Maillard reaction products or color. Intensively kilned malts are rich in melanoidins and poor in lipoxygenase activity. The anthocyanogen derived from barley is said to be unaffected by malting; however, in the case of pale lager malt, which is a major raw material of Japanese brands beer, kilning is usually insufficient to produce much melanoidins and additionally to inactivate the lipoxygenases.

The relationship between the reducing power and color developed during malting has also been investigated. The reducing power was increased associated with the increasing color of malt, but reducing activity per unit of color varied depending on the malt type. Lighter color malt gives higher reducing power per unit of color (Griffith \& Maule, 1997).

A number of recent studies have focused on the fate of precursors, enzymes and antioxidants of barley and malt. The content of lipids and the activities of related enzymes depend upon the variety of barley and its growing conditions. It is interesting that reducing the availability of oxygen during the stages of malting influences the degradation of lipids both enzymatically and autooxidatively (Kretschmer et al., 1995).

Staling-related compounds in malt increase in concentration, with the advance of modification (starch and protein degradation accompanying germination); increased proteolysis of malting brings higher levels of such staling-relating compounds and results in the development of intense stale flavor in the brewed beer (Lustig et al., 1995).

The activities of lipoxygenase (LOX) and polyphenoloxidase (PPO) were determined during the malting of ten barley varieties. LOX1 catalyzed a 9-hydroperoxide formation (a precursor of trans-2-nonenal), while LOX2 produced 13-hydroperoxide. Although weak PPO activity was detected, it disappeared by the time of kilning. The inhibitory activity against LOX was detected during the kilning process (Billaud et al., 1997).

Besides the problem of flavor stability, malting is also important in affecting other qualities of beer, for example, flavor, foam stability, colloidal stability, and yeast performance during fermentation.

\section{The Processes of Brewing}

\section{1) Mashing process}

In the process of "mashing", both the fermentable sugars and the other components are extracted from the malt. 
Mashing involves milling malt, soaking crushed malt and adjunct in water at increasing temperature steps, or "rests". The different temperatures at "rest" are set up to permit the highest activity of the different enzymes for the purpose. Oxidation during this process has been proved to be crucial for the quality of the beer and its flavor stability.

\section{(1) Milling systems}

Dry milling is still the most common system used, but sometimes, the husks can be crushed into fine pieces, making them inferior as filter material for lautering. Two other systems have been devised to keep the husks largely undamaged by the mill and to form an effective filter bed, namely, wet milling and moist conditioning. By the former method, the malt is soaked in water before milling, while by the latter method, the malt is sprayed with water just before milling. The wet milled malt is squeezed rather than ground by the mill, and grist with larger particles is formed. Enzymes often work incompletely on wet milled malt. In the case of moist conditioning, the husks are less damaged than in dry milling, and the endosperm is ground into grist particles of the appropriate size.

During milling, especially with the wet milling system, oxidation can proceed catalyzed by the relevant enzymes in malt (Herrmann et al, 1997). The discovery of lipid oxidation at the early stage of milling has led to the proposition that the malt could be sparged with $\mathrm{CO}_{2}$ or $\mathrm{N}_{2}$ before milling, thus creating an oxygen-free atmosphere (Van Waesberghe, 1997).

(2) Mashing

As the milled grist and water are mixed together (mashed), chemical, physical and enzymatic reactions proceed. The principal types of mashing are either "decoction" or "infusion". Most attention has been paid to the degradation of large molecular substrates, e.g., enzymatic hydrolysis of starch and protein to attain the maximum yield of wort. Detailed studies have revealed the principal reactions in the mash tun. The wort prepared by a decoction method tends to have increased polyphenols, dimethyl sulphide and some nonenzymatic browning substances (Narziß, 1992).

Concerning the oxidation taking place during mashing, the following are key conditions:

1. type of mashing system used,

2. duration and intensity of mash stirring,

3. heating energy, and

4. oxidizing effect, both of the oxygen already dissolved in the liquor and of any air which might get mixed into the mash.

These factors largely decide both the degree of oxidation and quality of the wort.

As additional information, oxygen uptake during mashing has been reported to decrease the activity of some enzymes (O'Rourke et al., 1992).

However, excessive prevention of wort oxidation has been demonstrated to degrade both haze stability and beer foam; thus, the optimization of wort quality is necessary with regards to the redox state (Brown et al., 1991).

The control of the mashing process is also critical, and several parameters have been developed to help regulate the process. The Polymerization Index (PI) is, possibly, the most popular indicator that is applied at the stages of malting and mashing. This index is calculated from the equation:

$$
\mathrm{PI}=\text { total polyphenols }(\mathrm{mg} / l) / \text { anthocyanogen }(\mathrm{mg} / l)
$$

The ratio reflects the degree of condensation of the polyphenols. For example, during the mashing process, if the air is successfully excluded from the system, the polymerization of polyphenols does not proceed. Thus a reducing-state mashing will give a lower PI than an oxidative-state mashing: the PI has thus been used to compare Ox/Red states. Other than the Ox/Red state of mashing, the degree of malt modification effects PI, that is, highly modified malt gives much soluble polyphenols, and the PI of wort from such malt is higher (Jerumanis, 1972). However, the case seems to be more complex, and the authors experienced a complete inconsistency in the results by highly controlled experiments. The definition and analytical methods for these substances might have to be reconsidered.

An integrated analytical apparatus was introduced to facilitate these studies. The Tannometer (Pfeuffer $\mathrm{GmbH}$, Germany) is a universal laboratory nephelometer by which tannoids, reducing power (FelII/Dipyridyl), and others can be determined (Chapon, 1993a). Its practical application in a brewhouse has been successfully achieved by Sapporo Breweries Ltd., and applied in the changes of pipe line design in brewhouses and accompanying facilities. Following this, methods and apparatus were studied and improved to fit the situation.

Analytical data obtained at the production site showed that reducing the oxygen taken up during the mashing process resulted in more antioxidants, such as tannoids, anthocyanogens and melanoidins, remaining in wort and the finished beer. The beer thus produced is fresher and tastier than that produced conventionally, and less stale flavor was developed after storage. Therefore, the hypothesis on beer staling has been confirmed and successfully exploited on a commercial scale; it is called the Anti-Oxidative Beer Production System (Takashio et al., 1998).

Other parameters are also important in the creation of stale-free beer. The $\mathrm{pH}$ of mash and wort is generally above optimum, since acidification of mash has been reported to improve flavor stability (besides the speed of mashing and lautering, brewhouse yield, fermentation performance and foam quality of beer). (Narziß, 1990; Narziß et al., 1990; Narziß, 1992).

\section{(3) Acidification of mash and flavor stability}

By employing acidified wort, many effects on the resulting beer have been observed, besides an improvement in taste stability, an improvement in bitterness, better diacetyl reduction during fermentation, a reduction in beer color and an increase in tannoids content. The reduction of mash $\mathrm{pH}$ brought also has some disadvantages such as an increased loss of bittering substances and higher contents of coagulable nitrogen. However, because of the buffer action of wort, the acidification of the mash did not spontaneously reduce the $\mathrm{pH}$ of the finished beer. A proposal was made to use biological acidification (employing cultured lactic acid bacteria) (Oliver-Daumen,1988; Oliver-Daumen et al, 1988).

\section{(4) Lautering}

Lautering is the last process of mashing where the wort (the 
aqueous solution of the extract) and the spent grain (the insoluble part) are separated from the mash by a filter composed of the spent grain. The yield of the extract is of the greatest concern, but the clarity is also important for beer quality. It has been reported that the flavor and flavor stability of beers, made from very bright wort, were distinctly better than beer made from turbid wort. This was explained by the presence of insoluble materials in the wort which consist partly of lipids, the precursors of staling flavor (Englmann \& Wasmuht, 1992).

\section{2) Hop boiling and subsequent processing}

Wort obtained by lautering is boiled for one hour or longer with hops. This process is important for the extraction and transformation of bitter components, and at the same time, some portion of the anthocyanogen is precipitated with the wort proteins, and this reduction of polyphenols can be monitored by measuring the tannoids. The progress of the Maillard reaction is also active during wort boiling. However, technical innovation of wort boiling had been driven by the economics of energy, and not necessarily by the quality of the beer. It has been reported that the use of certain new equipment can result in beers with off flavor and poor foam stability (Narziß et al., 1990).

(1) Removal of the hot break

After wort boiling, the spent hops may be removed by a hop strainer, a vessel with a sieve, although this practice is now uncommon. From the hot wort, trub (hot break, coarse break) is coagulated gradually and removed either by a coolship, a settling tank, a whirlpool, a centrifuge or by filtration.

\section{(2) Whirlpool practice}

The whirlpool is the most common technique employed. It is a vertical, cylindrical vessel, into which the wort is pumped tangentially by the wort casting pump. The hot break is removed as a cone-shaped sediment settled in the middle of the vessel bottom.

The oxidation of the wort proceeds also in this process, and holding the hot wort in the whirlpool for a longer period spoils the flavor stability of beer (Lustig et al., 1995).

Various compounds are formed in the wort during the hot stand in the whirlpool, some of them provide undesirable flavors in the beer and spoil the flavor stability. Vacuum evaporation has been devised to successfully remove such volatile compounds from the wort in the whirlpool (Lustig et al., 1997).

\section{The Fermentation Process}

The fermentation process is also important and has been intensively studied. At first, sufficient oxygen is supplied to the wort by aeration to permit the active metabolism of yeast. Oxygen in the wort is depleted immediately by yeast, and a reducing condition is maintained during fermentation until the yeast is removed by filtration. Anthocyanogens in the wort decrease during fermentation as a result of coprecipitation with protein, but a certain quantity remains in the beer and acts as an antioxidant. Enhanced flavor stability is thus brought about by increasing the reducing potential.

Higher temperatures during primary fermentation have been shown to be harmful, because the resulting beers contained higher concentrations of aging compounds, such as furfural, 5-methyl-2-furfural, 3-methyl-butanal and so on (Lustig et al., 1995).

In other words, the role of yeast is critical for both the quality and flavor stability of beer, and yeast handling procedures should be optimum. Malpractice in the storage of the yeast crop, namely, long storage periods, high temperatures, and others caused depletion of the yeast glycogen reserves, and the viability and fermentation capability of the yeast were seriously damaged by the time of pitching. Pitching with glycogen-deficient yeast has been shown to result in excessive production of diacetyl (the most important immature flavor of beer, vicinal diketones) and sulfur dioxide in beer and impaired amino acid uptake, which in turn led to slow fermentation and yeast growth and the appearance of off flavors (Pickerell et al., 1991; Oriet, 1996).

In considering the reduction of aldehydes during fermentation, yeast 3-methyl butanal reductases have been isolated and characterized (Van Nedervelde et al., 1997).

\section{1) Sulfites}

It has been noted that sulfur dioxide produced by yeast remains in the finished beer and plays a role as an antioxidant in delaying the staling reactions of beer.

Regarding the role of sulfites, there are contradictory theories:

1. They are recognized as an antioxidant which inhibit oxidation by which off-flavor compounds are produced (Barker et al., 1983; Nordiöv 1985).

2. It has also been shown that certain carbonyls, e.g., trans-2-nonenal, could be masked by the formation of bisulfite adducts (Nordiöv 1985; Drost et al. 1990).

3. Kaneda et al. (1996a) demonstrated that free sulfite and acetaldehyde bisulfite were detected by their specially developed analytical system with an HPLC, but none of the other aldehyde bisulfites were detected, and that not only sulfite dioxide, but its adduct with acetaldehyde, exhibited an activity, both as antioxidant and scavenger radical.

Thus, there are indications that free sulfite and acetaldehyde bisulfite protect against free radical reactions in beer. It has been further postulated that sulfites contribute to the flavor stability of beer by a radical scavenging activity rather than by a masking activity for staling flavor (Kaneda et al., 1996b)

\section{2) Sulfite metabolism in yeast}

To increase sulfite production during fermentation, various approaches have been reported. Sulfite is an intermediate in the assimilation of sulfur into methionine and cysteine. Some studies have revealed the relationship between the production of sulfur dioxide and amino acids metabolism. A study on the production of sulfur dioxide, the consumption of amino acids and the attenuation degree in a low alcohol beer wort revealed that sulfite production starts when four amino acids (asparagine, glutamine, serine and threonine) had been reduced to $10 \%$ or less of their initial concentrations and four other amino acids (aspartic acid, glutamic acid, lysine and methionine) had been reduced to between 30 to $40 \%$ of their 
initial concentrations. The other 12 acids were at greater than $50 \%$ of their initial values. Glucose addition increased sulfite production, but methionine addition reduced sulfite production (Gyllang et al., 1989).

\section{3) Gene engineering}

The practical application of the recombinant technique has, so far, been largely resisted by the food industry, but this new technology has shown itself to be a useful tool here also. Several methionine biosynthetic genes have been transformed by the plasmid into strains of yeast. The amount of sulfite synthesized during fermentation was increased by 2.5- to 20-fold (Korch et al., 1991).

Another genetic modification strategy was also successfully employed: the MET10 gene has been inactivated to reduce sulfite reductase activity in yeast cell, which produced significantly greater quantities of sulfite. The flavor stability of beers produced by the modified yeast was significantly improved (Hansen \& Kielland-Brandt, 1996).

\section{The Other Processes: Maturation, Filtration and Packaging}

\section{1) Maturation}

The objectives of the maturation, or conditioning phase after fermentation are considered by certain brewers as 1 . saturation of the beer with carbon dioxide under excess pressure, and 2. removal of trub and haze-forming components from the beer proceeding to the lagering vessels, where the yeast cells sediment slowly. At the end of fermentation and maturation, the dissolved oxygen content should have decreased to $0.01 \mathrm{ppm}$ or less.

\section{2) Filtration}

The yeast cells and other turbid materials are separated from the beer by a filter. There are several types of filter, including a cold sterile filtration system, and filter aids such as kieselguhr (although there present increasing problems regarding disposal after use) are used in the brewery.

As previously described, anthocyanogens are reactive and coagulate with proteins to form haze in beer during storage, especially in the presence of oxygen. Colloidal stabilization is as critical for beer as flavor stability. By filtration with specific adsorbents, both components of haze can be effectively removed to improve haze stability, that is,

1. the haze-forming proteins can be removed by adsorption onto silica gel or precipitation by gallotannins, and

2. the polyphenols can be specifically adsorped onto PVPP (polyvinylpolypyrrolidone).

However, excessive protein elimination might bring a defect in foam quality, and the reduction in the antioxidants content in beer should be performed only after considering the flavor stability implications.

Adsorption of phenolic constituents onto PVPP is employed practically in breweries, and detailed studies have been performed regarding the selectivity of the absorption reaction and others (McMurrough et al., 1995).

3) Oxygen control in beer transfer

Oxygen uptake during beer transfer and filtration has required special precautions:

1. avoidance of pulling in air when emptying the tank,

2. complete removal of air from all pipes and containers using oxygen-free water,

3. removal of air pockets in the pipes,

4. use of $\mathrm{CO}_{2}$ or $\mathrm{N}_{2}$ gas for counter pressure and flushing the pipes and container systems,

5. deaeration of the kieselguhr suspension in the dosing vessel by de-gassing with $\mathrm{CO}_{2}$,

6. separation of the first and the last runnings of beer during filtration, and others. These are only examples of the measures introduced and widely employed (Kunze, 1996; Meier, 1994).

Beer transfer technology in the breweries is summarized in the literature (Swihart, 1997) with a broad view, including the mathematical expression of the flow of piped liquids in a pipe.

\section{4) Packaging; plant \& practice}

Oxygen control in the packaging section has been extremely well-studied, and effective measures have been taken to reduce oxygen. Oxygen sensors, both in- and off-line, are familiar analytical apparatus there. It is now common to exclude air from bottles or kegs as far as possible, because even beer that retains ample antioxidants cannot escape from staling if the oxygen level is high. Generally beer with extra headspace air (e.g., oxygen content $0.5 \mathrm{mg} / l$ beer) is less stable than control beers. The design and operation of packaging lines are under constant development, year-byyear, in order to reduce oxygen pick up (Souster, 1995). Unlike Japan, where non-pasteurized beer is dominant, the influence of pasteurization is not debated in detail, but it is certain that normal pasteurization penalizes beer to the extent of at least one week of storage at $20^{\circ} \mathrm{C}$, as a rough guideline.

\section{5) Container materials}

The selection of the material for beer containers is also important for example, oxygen diffusing through the crown cap liner accelerates the oxidation of bottled beer. There is a study which found that the proportion of oxygen in the total gas diffusing into the bottle differs with each type of crown liner. A new lining material was invented, combining polyvinyl chloride (PVC) with special compounds that react with oxygen so as to form a selective barrier. It is claimed that they can totally prevent oxygen diffusing through the cap, thereby improving flavor stability (Teumac et al., 1990).

\section{Distribution of Packaged Beer: a Proposal for a Thermal Control Beer Transportation System}

Even when oxygen is expelled as much as possible, packaged beer in a bottle or can will show faster staling if the conditions under which it is held before consumption are not optimized.

Exposure to sunlight (especially UV), unsuitable temperature, and intense shaking are among the incidental causes that accelerate the deterioration of beer. During transportation on extremely hot summer days in Japan, the temperature of bottled beer can rise to as high as $45^{\circ} \mathrm{C}$ even in the shade. Our experiments, in which bottled and canned beer were kept at a temperature of $45^{\circ} \mathrm{C}$ for up to $6 \mathrm{~h}$, showed a faster staling 
reaction when followed by storage for a few weeks at $20^{\circ} \mathrm{C}$ than the same stored beer which had not been subjected to this short period of high temperature $\left(45^{\circ} \mathrm{C}\right)$. These findings are incorporated into Thermal Control Beer Transportation System, where trucks have been designed especially to avoid temperature extremes, and in combination with computeraided logistics, this system has been successfully employed nationally.

\section{Afterword}

As to the nature of the perfect beer, beer companies are trying to fully satisfy the consumers' demands for a wellbalanced product: one which has both freshness and flavor stability, satisfactory aroma and taste profile, good bitterness, color, and foam with a creamy texture. To match these conditions during the total shelf life of the product is a continuing challenge, and the advancement of technology and its appropriate application are the key to the future.

The authors of this paper believe, however, that there is still an unfortunate gap between what we do in the scientific laboratories and what we can practically achieve in the breweries. Additionally, some of the ideas and theories proposed in this paper are still controversial. However, by reviewing them, perhaps further stimulation and discussion will take place among those colleagues who have an interest in this extremely important field of brewing science.

Acknowledgments The authors wish to thank Dr. James P. Murray, Brewing Research International, Surrey, United Kingdom for his kind discussion. Regarding the bibliographic check and the information on organic chemistry, the authors must also express their gratitude for the help of Dr. Chikako Shimizu, Brewing Research Laboratories, Sapporo Breweries Ltd.

\section{Literature}

André, J.C. and Moll, M. (1986). A new approach to the kinetics of beer oxidation: From physical chemistry to industrial brewing. $J$. Am. Soc. Brew. Chem., 44, 151-157.

Araki, S., Kaneda, H., Kimura, T., Takashio, M., Tamaki, T. and Shinotsuka, K. (1998). Estimation of antioxidative activity and its implication for beer flavor stability. Am. Soc. Brew. Chem. Ann. Meeting, Boston.

Bamforth, C.W. and Parsons. R. (1985). New procedures to improve the flavor stability of Beer. J. Am. Soc. Brew. Chem., 43, 197-202.

Baxter, E.D., Morris, T.M. and Picksley, M.A. (1987). Low proanthocyanidin malts for production of chilled and filtered or fined beer. J. Inst. Brew., 93, 387-391.

Barker, R.L., Gracey, D.E.F., Irwin, A.J., Pipasts, P. and Leiska, E. (1983). Liberation of staling aldehydes during storage of beer. $J$. Inst. Brew., 89, 411-415.

Billaud, C., Garcia, R., Boivin, P., and Nicolas, J. (1997). Evolution des activités lipxygénasique et polyphénoloxydasique de différentes variétés d'Orge au cours du maltage. Proc. Eur. Brew. Conv., Maastricht, pp. 159-166.

Blockmans, C., Masschelen, C.A. and Dereux, A. (1979). Origine de certains composés carbonylés au ceurs du viellissement de la biére. Proc. Eur. Brew. Conv., Berlin, pp. 279-291.

Boivin, P. and Martel, C. (1991). Proteolysis during malting. Ferment, 4, $182-186$

Boivin, P., Malanda, M., Maillard, M.N., Berset, C., Richard, H., Hugues, M., Richard-Forget, F. and Nicolas, J. (1995). Role of the natural antioxidants of malt in the organoleptic stability of beer. Proc. Eur. Brew. Conv., Brussels, pp. 159-168.

Brown, J.W., Murray, J.P., Taylor, D.G. and Westwood, K. (1991). Relationship between wort oxidation and beer quality parameters.
Proc. Conv. Inst. Brew. (Cent. \& South African Sect.), Victoria Falls, pp. 173-179.

Chapon, L. (1993a). Der begriff Tannoide. Brauwissenchaft, 46, 263279.

Chapon, L. (1993b). Nephelometery as a method for studying the relations between polyphenols and proteins. J. Inst. Brew., 99, 4956

DeBuck, A., Aerts, G., Bonte, S., Dupire, S. and Van den Eynde, E. (1997). Relation between lipoxygenase extraction during brewing, reducing capacity of the wort and the organoleptic stability of beer. Proc. Eur. Brew. Conv., Maastricht, pp. 333-340.

Drost, B.W. (1981). Geschmaksstabilität. Brauwelt, 121, 786, 788-790.

Drost, B.W., van den Berg, R., Freijee, F.J.M., van der Velde, E.G. and Hollemans, M. (1990). Flavor stability. J. Am. Soc. Brew. Chem., 48, 124-131.

Esterbauer, H. and Schauenstein, E. (1977). Isomere Trihydroxyoctadecensäuren in Bier: Beweise für ihr vorkommen und ihre quantitative Bestimmung. Z. Lebensm.-Unters. Forssch., 164, 255-259.

Englmann, J. and Wasmuht, K. (1992). Einfluß der Abläuterung auf Gärung und Biereigenschaften. Brauwelt, 132, 1878, 1880-1884.

Furusho, S., Kobayashi, N., Nakae, N., Takashio, M., Tamaki, T. and Shinotsuka, K. (1998). A developed descriptive sensory tests reveals beer flavor change during storage. (The $111^{\text {th }}$ Anniversary Convention of Master Brewers Association of the Americas), Minneapolis.

Galic, K., Palic, A. and Cikovic, N. (1994). On the redox potential in brewing process. A Review, Monatsschr. Brauwiss., 47, 124-128.

Granshaw, J.W. (1967). Phenolic constituents of beer and brewing materials. J. Inst. Brew. 73, 258-270.

Griffith, J. and Maule, A.P. (1997). The effect of different cereal coloured malts on reducing power during the brewing process. Proc. Eur. Brew. Conv., Maastricht, pp. 267-274.

Grigsby, J.H. and Palamand, S.R. (1976). Studies on the staling of beer: The use of 2-thiobarbituric acid in the measurement of beer oxidation. J. Am. Soc. Brew. Chem., 34, 49-55.

Gyllang, H., Winge, M. and Korch, C. (1989). Regulation of sulphur dioxide during fermentation. Proc. Eur. Brew. Conv., Zurich, pp. 347-354.

Hagiwara, Y. (1997), A method to reduce beer staling. Japan Kokai Tokkyo Koho, 97, 234054 (Sep. 9).

Hansen, J. and Kielland-Brandt, M.C. (1996). Inactivation of met 10 in brewers' yeast specifically increases $\mathrm{SO}_{2}$ formation during beer production. Nat. Biotech., 14, 1587-1591.

Harris, G. (1956). General composition of non-biological hazes of bears and some factors in their formation II. Chromatographic separation of hop and molt tannins. J. Inst. Brew., 62, 390-406.

Harris, G. and Rickettes, R.W. (1959). Studies on non-biological haze of beer VIII, J. Inst. Brew., 65, 331-333.

Herrmann, H., Kantelberg, B. and Wiesner, R. (1997). Schrotsysteme mit Weichkonditionierung-Verfahrensweisen - neue Erkenntniße. Brauwelt, 137, 493-494, 503.

Hashimoto, N. and Kuroiwa, Y. (1975). Pathways for the formation of volatile aldehydes during storage of bottled beer. Rept. Res. Lab. Kirin Brew, 18, 1-11.

Hugues, M., Boivin, P., Gauillard, F., Nicolas, J., Thiry, J.-M. and Richard-Forget, F. (1994). Two lipoxygenases from germinated barley - Heat and kilning stability. J. Food Sci, 59, 885-889.

Huige, N.J. (1993). Progress in beer oxidation control. In "Beer and Wine Production (ACS Symp. Ser. 536)." ed. by B.H. Gump. American Chemical Society, Washington D.C., pp. 64-97.

Jerumanis, J. (1972). Über die Veränderung der Polyphenols im Verlauf des Mälzens und Maischens. Brauwissenshaft. 25, 313-322.

Kamimura, M. and Kaneda, H. (1993). Shelf Life of Beer. In "Shelf Life Studies of Foods and Bevarages", ed. by Charalambous, G. Chemical, Biological, Physical and Nutritional Aspects (Dev. Food Sci.), Elsevier, Amsterdam, pp. 821-889.

Kaneda, H., Kano, Y., Osawa, T., Kawakishi, S. and Kamada, K. (1989). The role of free radicals in beer oxidation. J. Am. Soc. Brew. Chem., 47, 49-53.

Kaneda, H., Kano, Y., Kamimura, M., Osawa, T. and Kawakishi, S. (1990). Evaluation of beer deterioration by chemiluminescence. $J$. Food Sci., 55, 1361-1364. 
Kaneda, H., Kobayashi, N., Furusho, S., Sahara, H. and Koshino, S (1995). Reducing activity and flavor stability of beer. Tech. Q. Master Brew. Assoc. Am., 32, 90-94.

Kaneda, H., Takashio, M., Osawa, T., Kawakishi, S. and Tamaki, T. (1996a). Behavior of sulfites during fermentation and storage of beer. J. Am. Soc. Brew. Chem., 54, 115-120.

Kaneda, H., Kobayashi, N., Takashio, M. and Tamaki, T. (1996b). Contribution of sulphite to flavour stability of beer. Proc. Conv. Inst. Brew. (Asia Pacific Sect.), Singapore. pp. 116-119.

Klimovitz, R.J. and Kindraka, J.A. (1989). The impact of various antioxidants on flavor stability. Tech. Q. Master Brew. Assoc. Am., 29, 70-74.

Korch, C., Mountain, H.A., Gyllang, H., Winge, M. and Brehmer, P. (1991). A mechanism for sulfite production in beer and how to increase sulfite levels by recombinant genetics. Proc. Eur. Brew. Conv., Lisbon, pp. 201-208.

Kossa, T., Bahri, D. and Tressl, R. (1979). Aromastoffe des Malzes und deren Beitrag zum Bieraroma. Mschr. Brauerei., 32, 249-252, 254.

Kretschmer, H., Miedaner, H., Narziss, L. and Back, W. (1995). Der Einfluß des Sauerstoffgehaltes beim Keimen, Schwelken und Darren auf die Qualität von Malz und Bier. Proc. Eur. Brew. Conv., Brussels, pp. 507-513.

Kunze. W. (1996). Technology Brewing and Malting, International Edition, ed. by W. Kunze, VLB Berlin, Verlagsabteilung pp. 403 405 .

Letters, R. (1992). Lipids in brewing, friend or foe? Ferment, 5, 268 274.

Lustig, S., Miedaner, H., Narziss, L. and Back, W. (1995). BeeinfluBung alterungsrelevanter Aromastoffe dürch technologische Maßsnahmen bei der Malz-, Würze- und Bierbereitung. Proc. Eur. Brew. Conv., Brussels, pp. 499-506.

Lustig, S., Kunst, T. and Hill, P. (1997). Einfluß einer Vekuumverdampfung vor der Würzekühlung auf Bierqualität und Geschmacksstabilität. Proc. Eur. Brew. Conv., Maastricht, pp. 341-348.

Martel, C., Kohl, S. and Boivin, P. (1991). Lipoxygenase: Origine, evolution et consequence dans la filiere malterie-brasserie. Proc. Eur. Brew. Conv., Lisbon, pp. 425-432.

Masschelein, C.A. (1980). Rôle des réactions photochimques dans l'instabilité organoleptique de la bière après soutirage. Cerevisia, $\mathbf{5}$, 107-110.

McMurrough, I., Madigan, D. and Smyth, M.R. (1995). Adsorption by polyvinylpolypyrrolidone of catechins and proanthocyanidins from beer. J. Agric. Food Chem., 43, 2687-2691.

Meier, E. (1994). Filtration. Vorteile der Vor- und Nachlaufverwertung. Brauindustrie, 79, 744-745.

Meilgaard, H. (1972). Stale flavor carbonyls in brewing. Brew. Dig., 47, $48-52,54,56,57,62$

Moll, M. (1987). Brewing Science, ed. by Pollock, J.R.A (Academic Press), London, Vol. 3. 31-49.

Moll, M. and Moll, N. (1990). Voies principales de formation des composés carbonylés pan condensation aldolique. Brau. Rundsch., 101, 99-103.

Narziß, L. (1990). Das maischverfahren als Faktor zur Differenzierung der Biere. Brau. J., 108, 44-51.

Narziß, L. (1992). Qualitative und quantitative Aspekte beim Maischen. Brauwelt, 132, 1072, 1074-1082, 1091.

Narziß, L., Miedaner, H. and Graf, H. (1985). Carbonyle und Alterung des Bieres; Teil 2: Einfluß einiger technologischer parameter. Brauwiss., 38, 472-477.

Narziß, L., Miedaner, H. and Schneider, F. (1990). Einige Aspekte zur Technologie der Wuerzekochung aus heutiger Sicht. Brauwelt, 130, $1618-1628$.

Nordiöv, H. (1985), Formation of sulphur dioxide during beer fermentation. Proc. Eur. Brew. Conv., Helsinki, 291-298.

O'Rourke, T., Brown, J.W., Theaker, P.D. and Archibald, H.W. (1992). The effect of oxidation during wort production on the processing and flavour of beer. Proc. Conv. Inst. Brew., (Aust. N.Z. Sect.), Melbourne, pp. 52-58.
Oliver-Daumen, B. (1988). Die Biologische Säuerung beim Brauprozeß. Teil 1: Eine Literaturuebersicht. Brauwelt, 128, 762-768.

Oliver-Daumen, B., Bach, W., Seidenschwan, A. and Schwedhelm, R. (1988). Die Biologische Saeuerung beim Brauprozeß. Teil 3: Grosstechnische Versuche, deren Auswirkungen und Bewertung). Brauwelt, 128, 2192, 2194, 2196, 2198, 2200.

Oriet, P. (1996). Pflege von Betriebshefe. Brau. Rundsch. 107, 161- 164.

Owades, J.L. and Jakovac, J. (1966). Study of beer oxidation with O18. Proc. Am. Soc. Brew. Chem., p. 180.

Piendl, A., Westner, H. and Geiger, E. (1981). Nachweis und Trennung von Aldehyden in Bier mittels Hochdruclflüssigkeitschromatographie (HPLC). Brauwiss. 34, 301-307.

Pickerell, A.T.W., Hwang, A. and Axcell, B.C. (1991). Impact of yeast handling procedures on beer flavour development during fermentation. J. Am. Soc. Brew. Chem., 49, 87-92.

Shimizu, C. Nakamura. Y, Miyai, K. Takashio, M. and Shinotsuka, K. (1998). Control of 5-hydroxymethyl furfural (5-HMF) formation during mashing and fermentation. Am. Soc. Brew. Chem. Ann. Meeting. (Boston).

Sorgl, J., Kosar, K., Mikyska, A. and Bousová, P. (1997). Change occuring in polyphenol substances content during wort production. Proc. Eur. Brew. Conv., Maastricht, pp. 275-282.

Souster, L.J. (1995). Line performance with respect to flavour stability. Brewer, 81, 493-494, 496-497.

Stenroos, L., Wang, P., Siebert, K. and Meilgaard, M. (1976). Origin and formation of 2-nonenal in heated beer. Tech. Q. Master Brew. Assoc. Am., 13, 227-232.

Swihart. M.S. (1997). Healthy beer transfers: A review of sound brewing practice and design. Tech. Q. Master Brew. Assoc. Am.,34, $107-114$

Takashio, M., Kimura, T., Araki, S., Furusho, S., Kaneda, H., Kobayashi, N., Maeba, H., Miyai, K., Nakae, N., Nakamura, Y., Shimizu, C., Tamaki, T. and Shinotsuka,K. (1998). Protective production of beer against oxidation: Practical studies at a pilot brewing. Am. Soc. Brew. Chem. Ann. Meeting. (Boston).

Teumac, F.N., Ross, B.A. and Rassouli, M.R. (1990). Air ingress through bottle crowns. Tech. Q. Master Brew. Assoc. Am., 27, 122 126.

Thum, B., Miedaner, H., Narziß, L. and Back, W. (1995). Bildung von "Alterungscarbonylen"-mögliche Mechanismen und Bedeutung bei der Bierlagerung. Proc. Eur. Brew. Conv. Brussels, pp. 491-498.

Van de Meerssche, J., Blockmans, C., Devreux, A. and Masschelein, C.A. (1983). Formation de trans-2-nonénal par photooxidation des acides octadécénoques hydroxylés. Proc. Eur. Brew. Conv., London, pp. $525-532$

Van Nedervelde, L., Verlinden, V., Philipp, D., and Debourg, A. (1997). Purification and characterization of yeast 3-methyl butanal reductases involved in the removal of wort carbonyls during fermentation. Proc. Eur. Brew. Conv., Maastricht, pp. 447-454.

Van Waesberghe, J. (1996). Anti-oxidants and pro-oxidants in preprocessed brewing ingredients. Tech. Q. Master Brew. Assoc. Am., 33, 96-101.

Van Waesberghe, J.W.M. (1997). New milling and mashing-in Systems, developed to avoid the initiation of lipid oxidation at the start of the lager beer brewing process. Proc. Eur. Brew. Conv., Maastricht, pp. 247-256.

Van Waesberghe, J.W.M. and van Waesberghe, W.J.J.M. (1994). The impact of lipoxygenase and microflora management on flavor. Eur. Brew. Conv. Monogr., XXIII, Symposium on Malting Technology, Andernach, pp. 44-66.

Walters, M.T., Heasman, A.P. and Hughes, P.S. (1997a). Comparison of $(+)$-catechin and ferulic acid as natural antioxidants and their impact on beer flavor stability. part 1: Forced-Aging. J. Am. Soc. Brew. Chem., 55, 83-89.

Walters, M.T., Heasman, A.P. and Hughes, P.S. (1997b). Comparison of $(+)$-catechin and ferulic acid as natural antioxidants and their impact on beer flavor stability. part 2: Extended storage trials. J. Am. Soc. Brew. Chem., 55, 91-98. 